\title{
Design and Analysis of Butterfly Valve
}

\author{
R.Manikandan', R.Karthikeyan ${ }^{2}$, N.Elumalai ${ }^{3}$ \\ 1,2,3 Assistant Professor, Department of Aeronautical Engineering, Bharath Institute of Higher Education and \\ Research, Chennai.
}

Article History: Received: 11 January 2021; Accepted: 27 February 2021; Published online: 5 April 2021

\begin{abstract}
The main objective of this project is shape optimization and structural stability of the butterfly valve for metallic and nonmetallic materials butterfly valve is mostly used in the engine carburetors need to make structural stability and shape optimization plays the main role for this component, design modifications and material comparative analysis done in ANSYS Structural modules and find the optimized shape through stress, strain and deformation results

Keywords: Butterfly valve, design optimization, engine components, FEA

\section{INTRODUCTION:}

A butterfly valve is a shut-off valve with a relatively basic configuration. In the locked state, a disc covers the hole of the valves while in the available spot, the disc is rotated to allow the flow. A quarter turn takes the valve from fully open to fully closed or reverse location and thus the butterfly valve allows for easy opening and closing.

Butterfly valves may be used for a wide variety of applications in the areas of water supply, waste management, fire protection or gas supply, gas and oil industries, in fuel handling systems, power generation etc. Some of the benefits for this type of valve are the basic structure that does not take up too much room, and the light weight and lower cost relative to other valve designs.

The valves can be operated by means of handles, gears or actuators in conjunction with any particular need. The main objective of this project is shape optimization and structural stability of the butterfly valve for metallic and nonmetallic materials butterfly valve is mostly used in the engine carburetors need to make structural stability and shape optimization plays the main role for this component, design modifications and material comparative analysis done in ANSYS Structural modules and find the optimized shape through stress, strain and deformation results.
\end{abstract}

\section{MODELING}

Modeling of butterfly valve done in CATIA software and the modification is elliptical shape can be added in existing plate and elliptical shape is removed from the plate

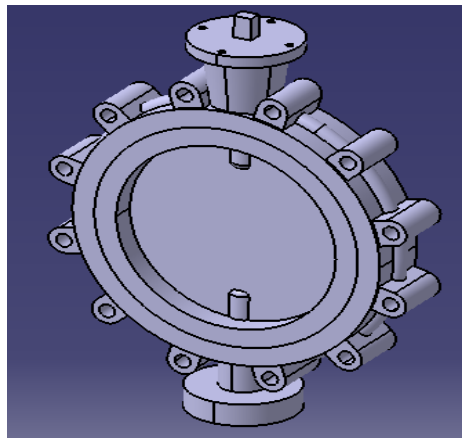

3D model of Butterfly valve

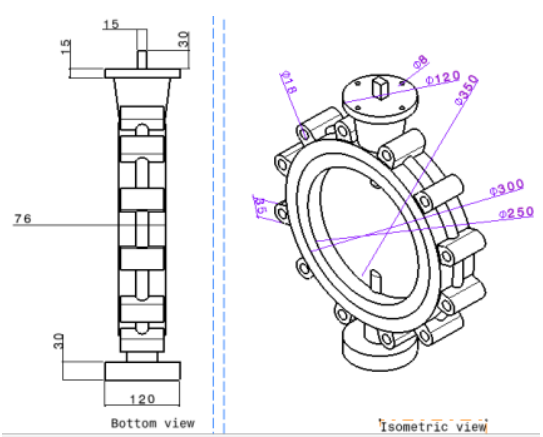

2D model of butterfly valve

\section{Results and discussion}

TOTAL DEFORMATION

\section{Actual size}




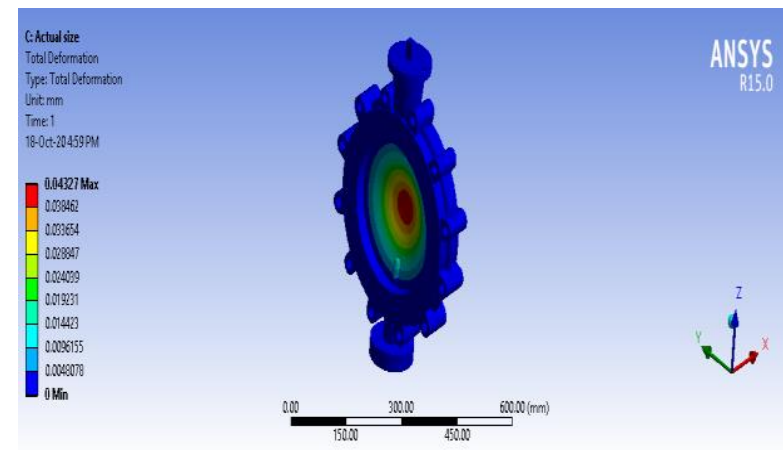

Total deformation for aluminum alloy

\section{Modification 1}

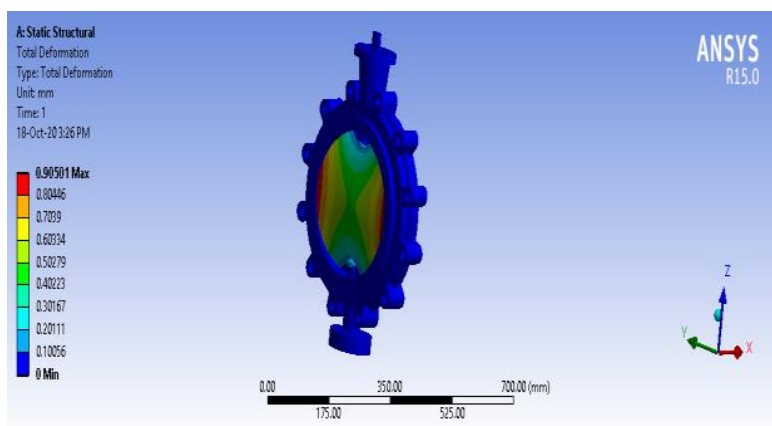

Total deformation for aluminum alloy

\section{Modification 2}

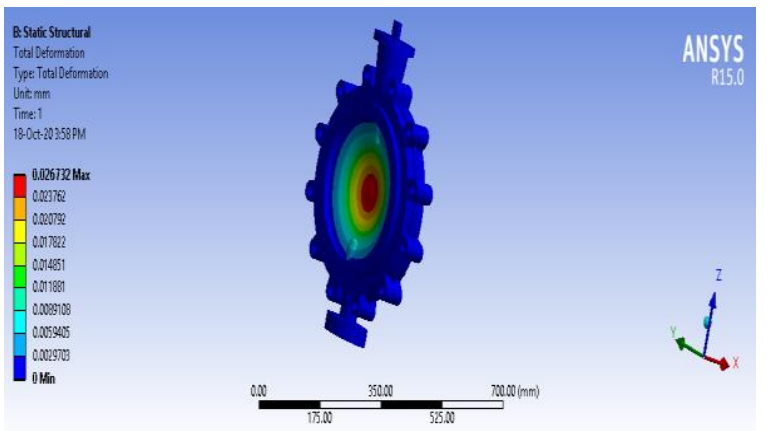

Total deformation for aluminum alloy

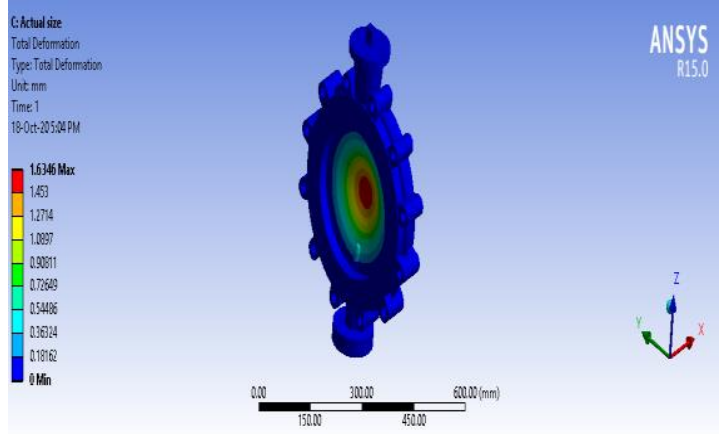

Total deformation for polypropylene

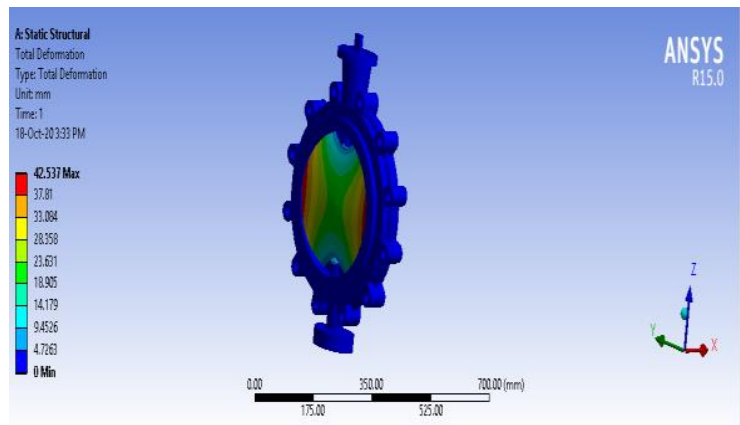

Total deformation for polypropylene

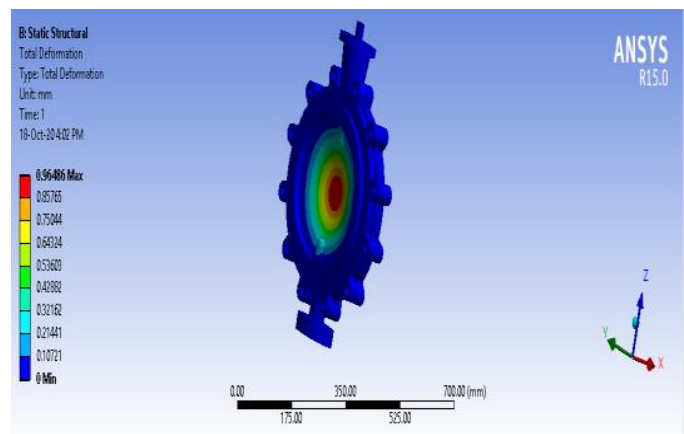

Total deformation for polypropylene

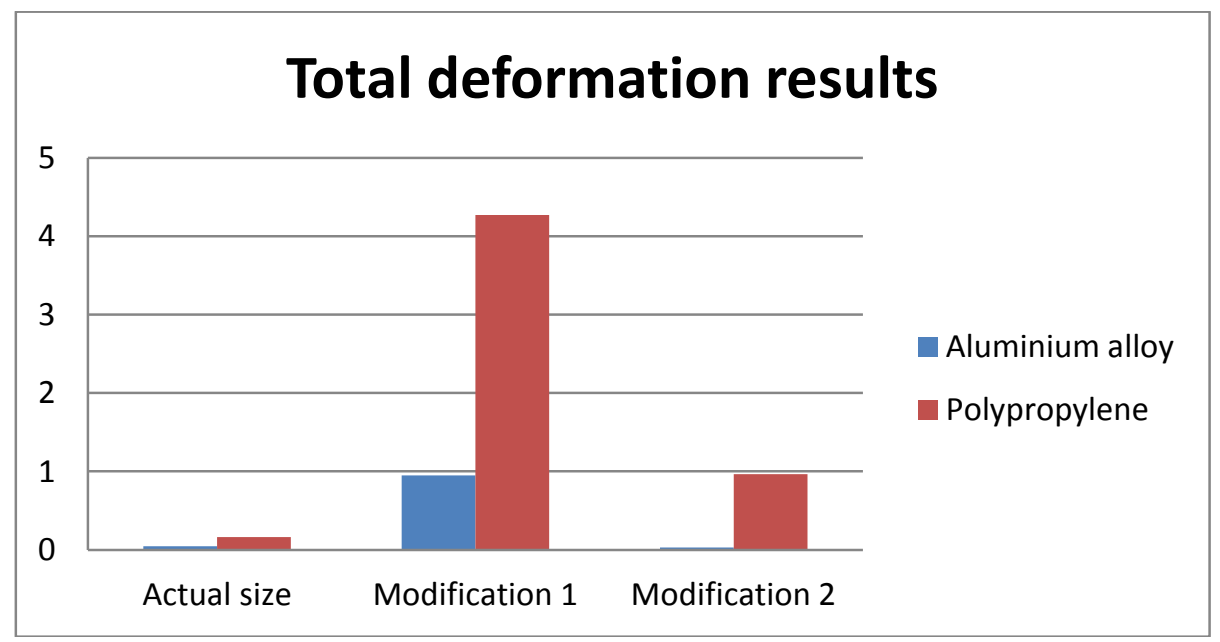




\begin{tabular}{|c|c|c|}
\hline Total deformation & Aluminum alloy & Polypropylene \\
\hline Actual size & 0.04327 & 0.16346 \\
\hline Modification 1 & 0.9501 & 4.27 \\
\hline Modification 2 & & 0.96486 \\
\hline
\end{tabular}

\section{STRESS INTENSITY}

\section{Actual size}

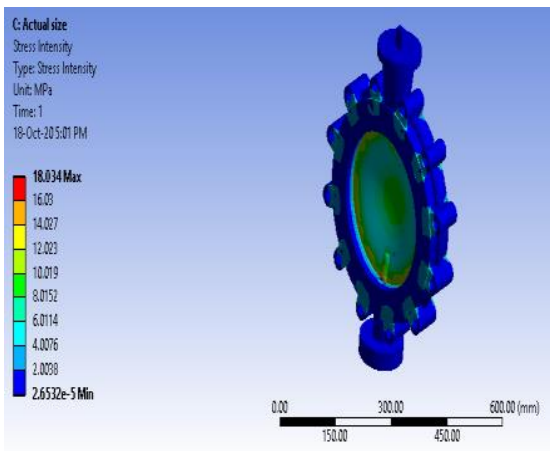

Stress intensity for aluminum alloy

\section{Modification 1}

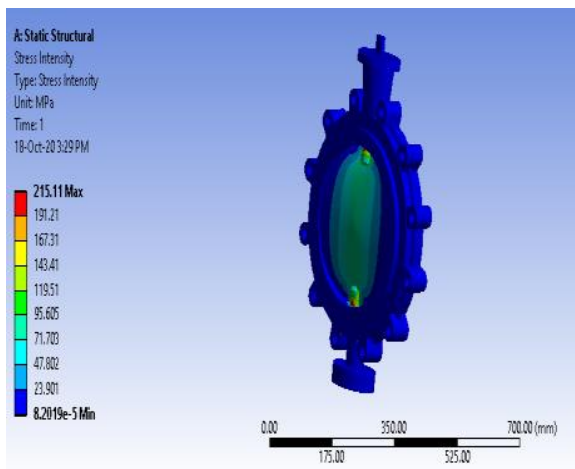

Stress intensity for aluminum alloy
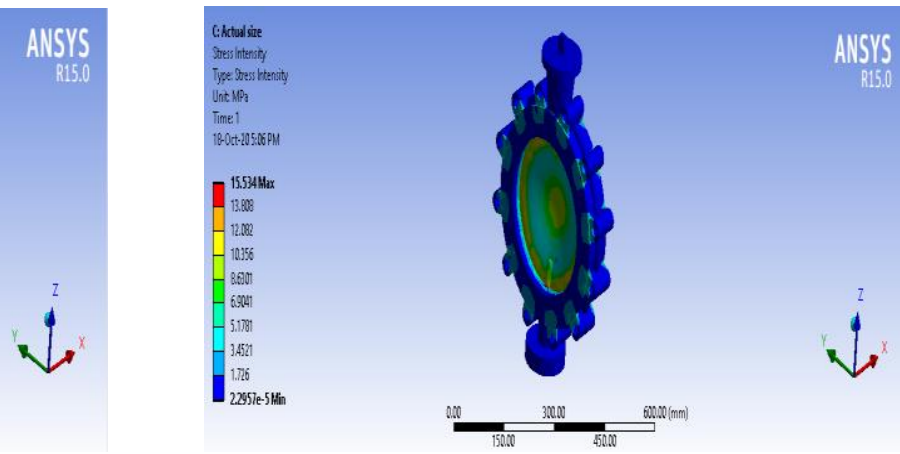

Stress intensity for polypropylene

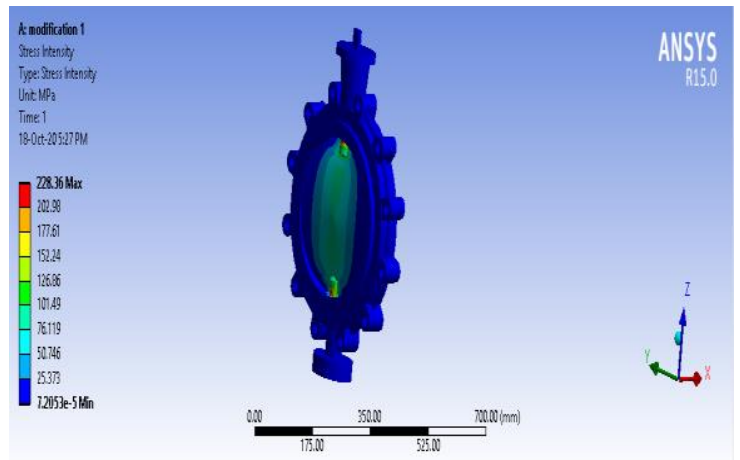

Stress intensity for polypropylene 


\section{Modification 2}

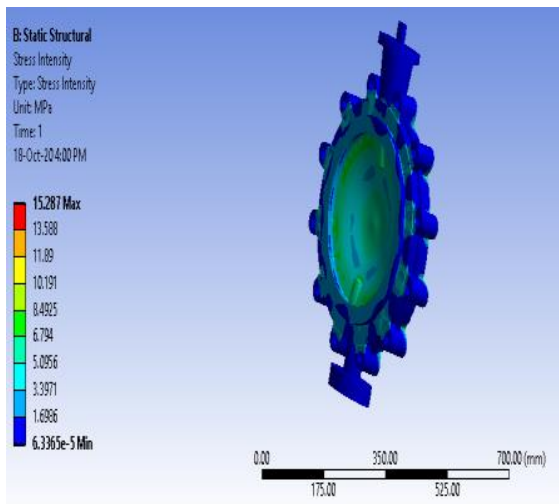

Stress intensity for aluminum alloy

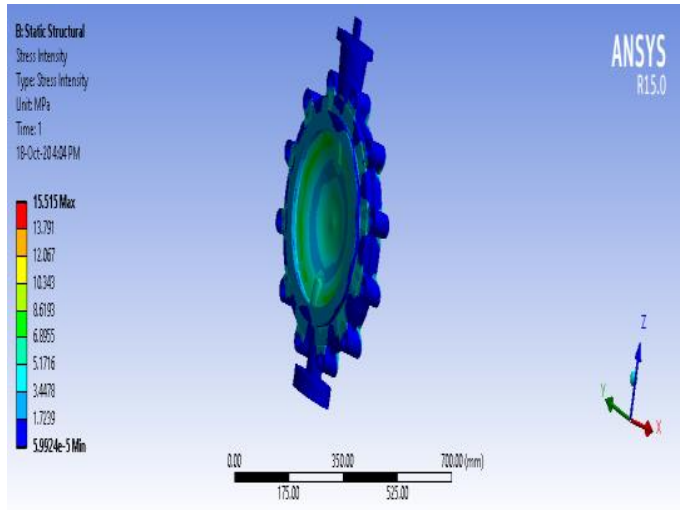

Stress intensity for polypropylene

\section{Stress intensity}

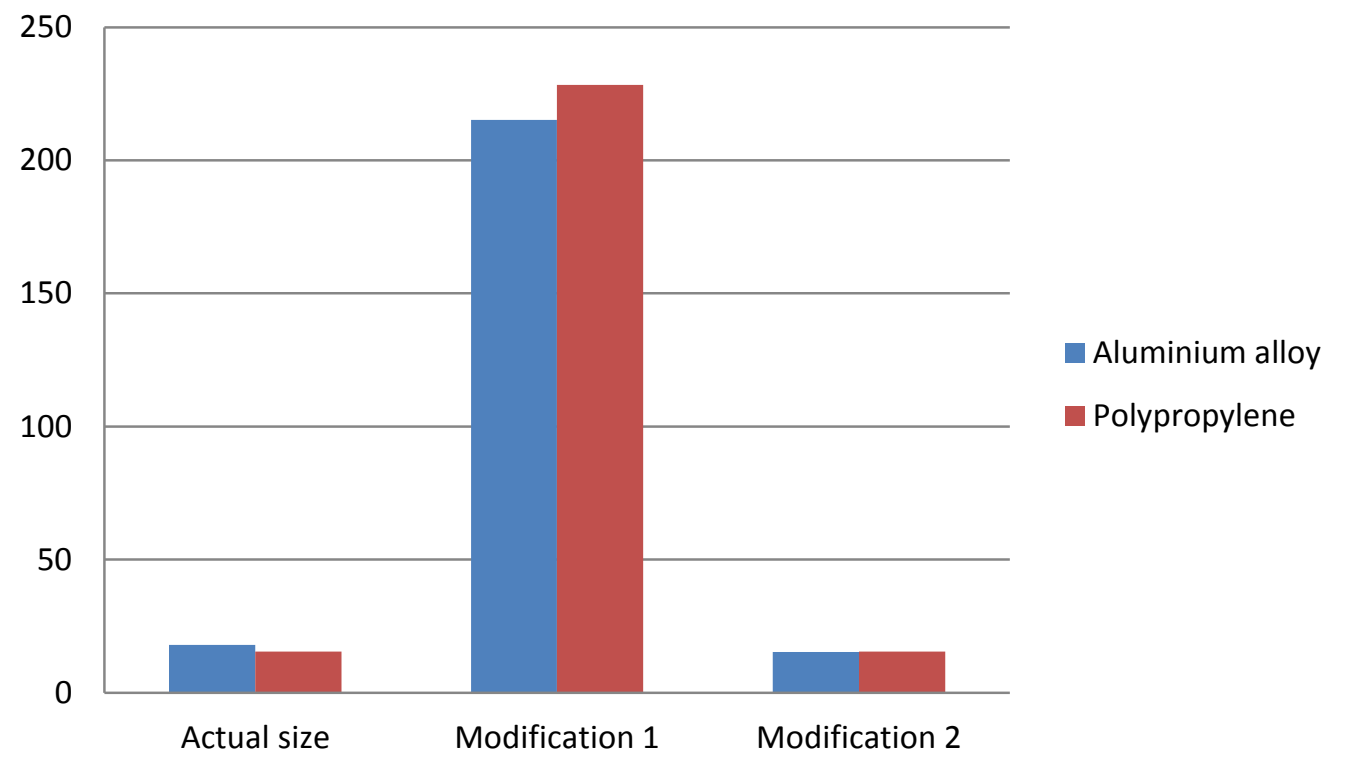

\begin{tabular}{|c|c|c|}
\hline Stress intensity & Aluminum alloy & Polypropylene \\
\hline Actual size & 18.034 & 15.534 \\
\hline Modification 1 & 215.11 & 228.36 \\
\hline Modification 2 & 15.287 & 15.515 \\
\hline
\end{tabular}




\section{STRAIN INTENSITY}

\section{Actual size}

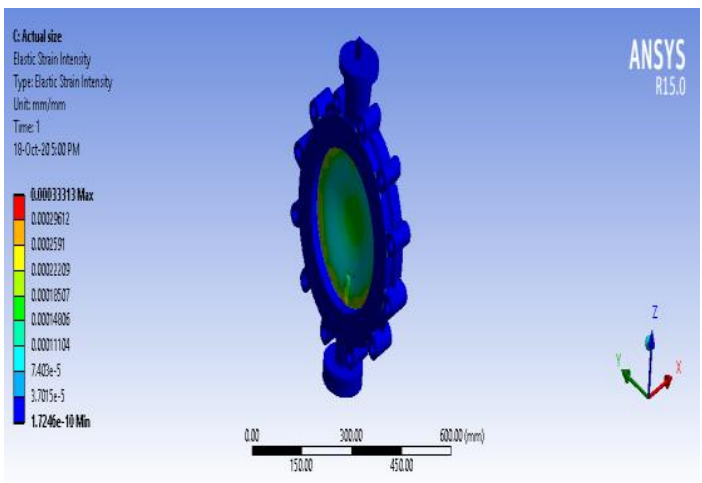

Strain intensity for aluminum alloy

\section{Modification 1}

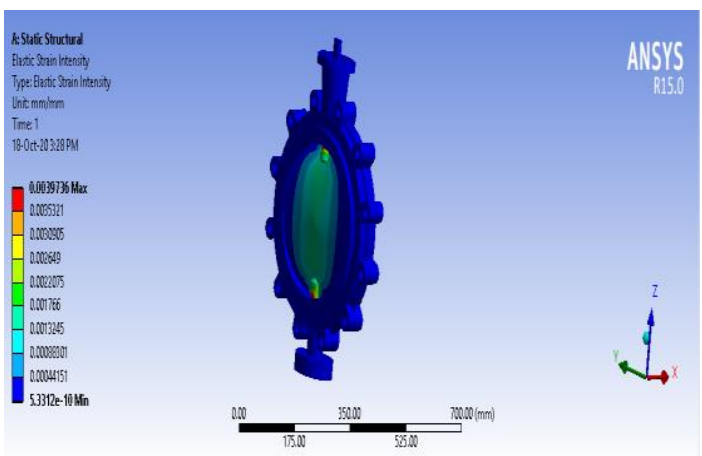

Strain intensity for aluminum alloy

\section{Modification 2}

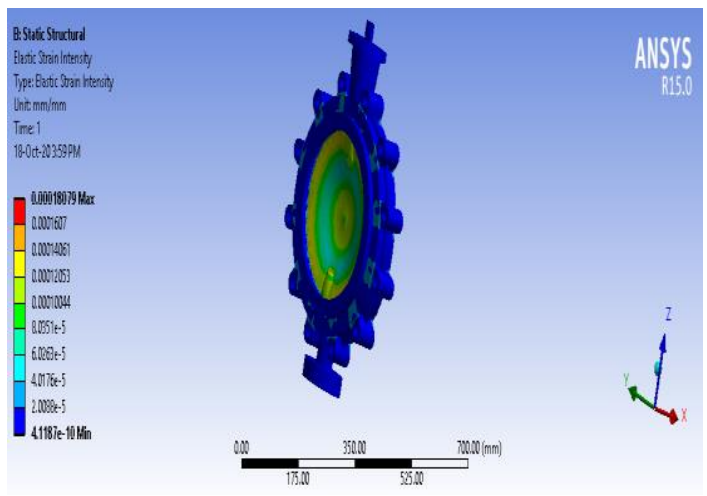

Strain intensity for aluminum alloy

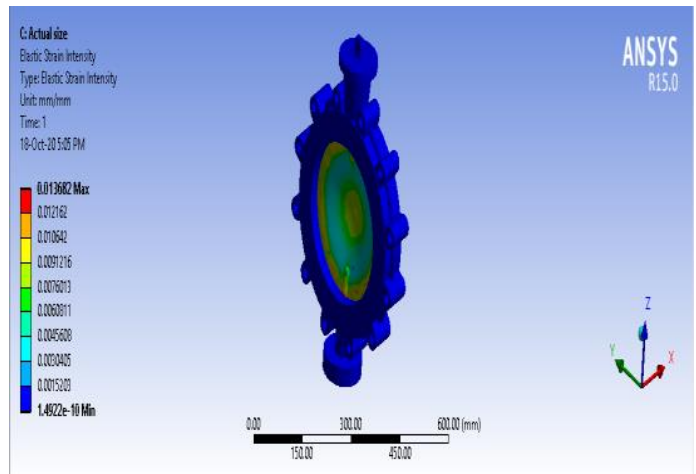

Strain intensity for polypropylene

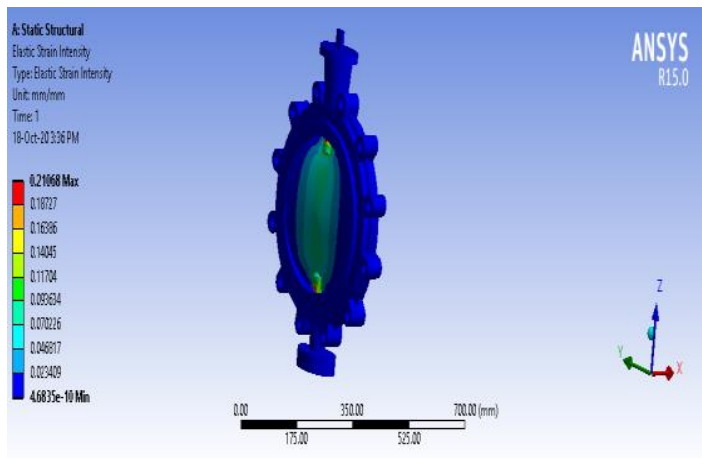

Strain intensity for polypropylene

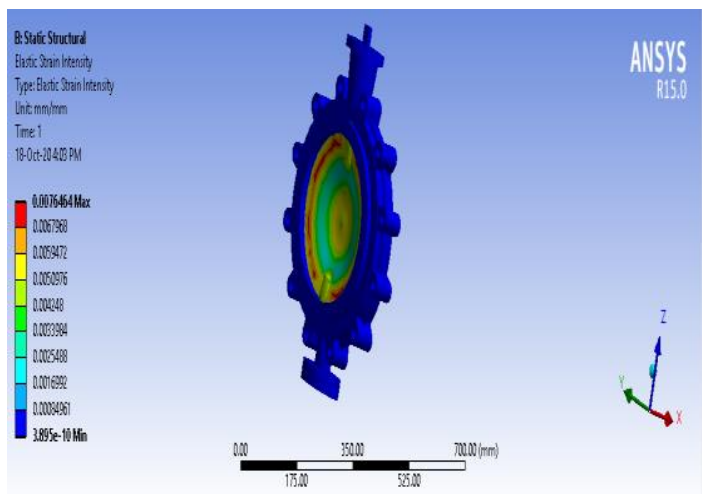

Strain intensity for polypropylene 


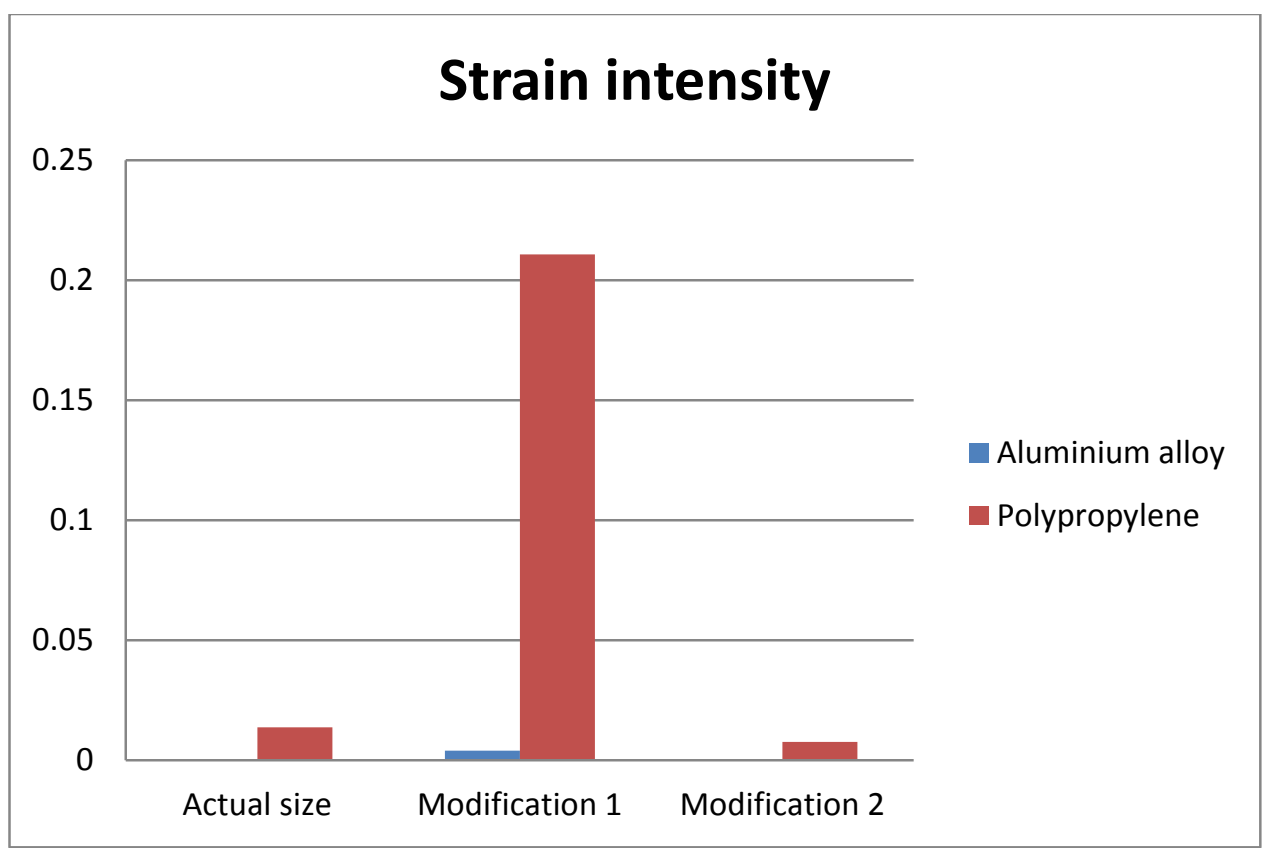

\begin{tabular}{|c|c|c|}
\hline Strain intensity & Aluminum alloy & Polypropylene \\
\hline Actual size & 0.00033313 & 0.013682 \\
\hline Modification 1 & 0.0039736 & 0.21068 \\
\hline Modification 2 & 0.00018079 & 0.0076464 \\
\hline
\end{tabular}

\section{EQUIVALENT ELASTIC STRAIN}

\section{Actual size}

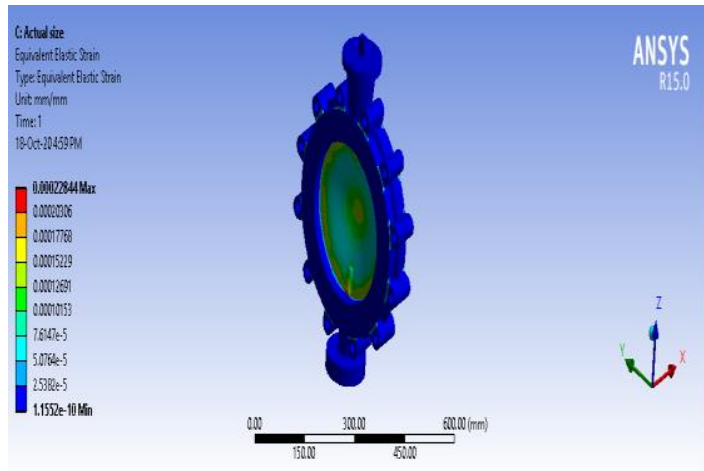

Equivalent elastic strain for aluminum alloy

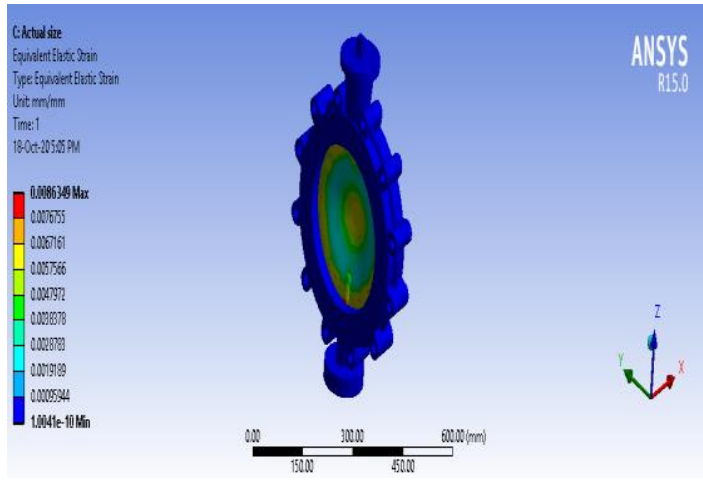

Equivalent elastic strain for polypropylene 


\section{Modification 1}

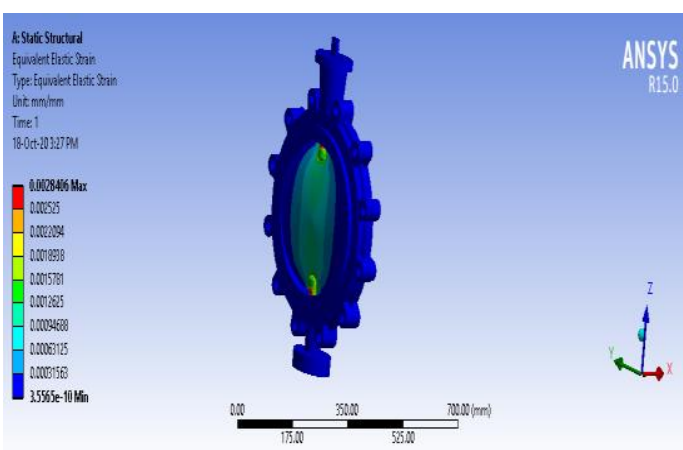

Equivalent elastic strain for aluminum alloy

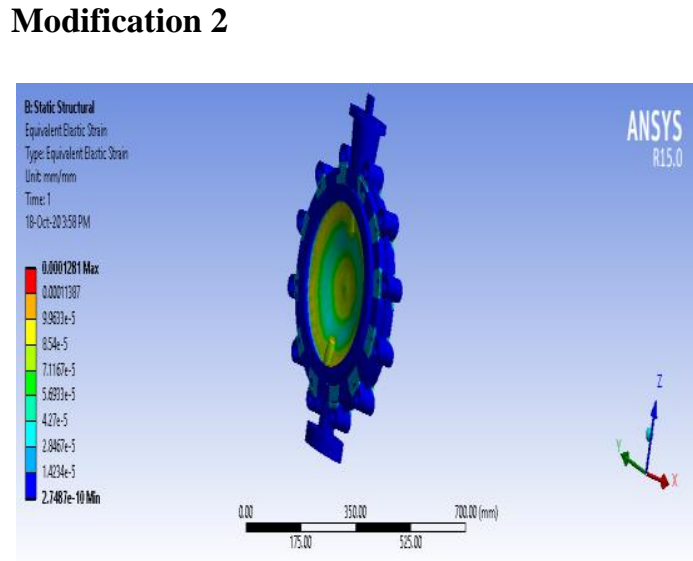

Equivalent elastic strain for aluminum alloy

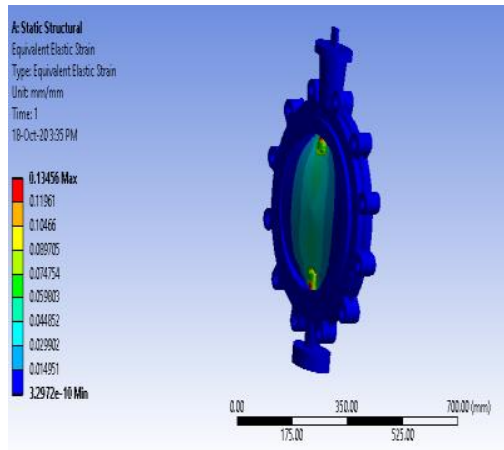

ANSYS

Equivalent elastic strain for polypropylene

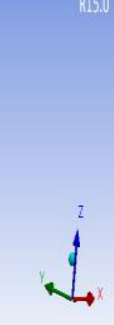

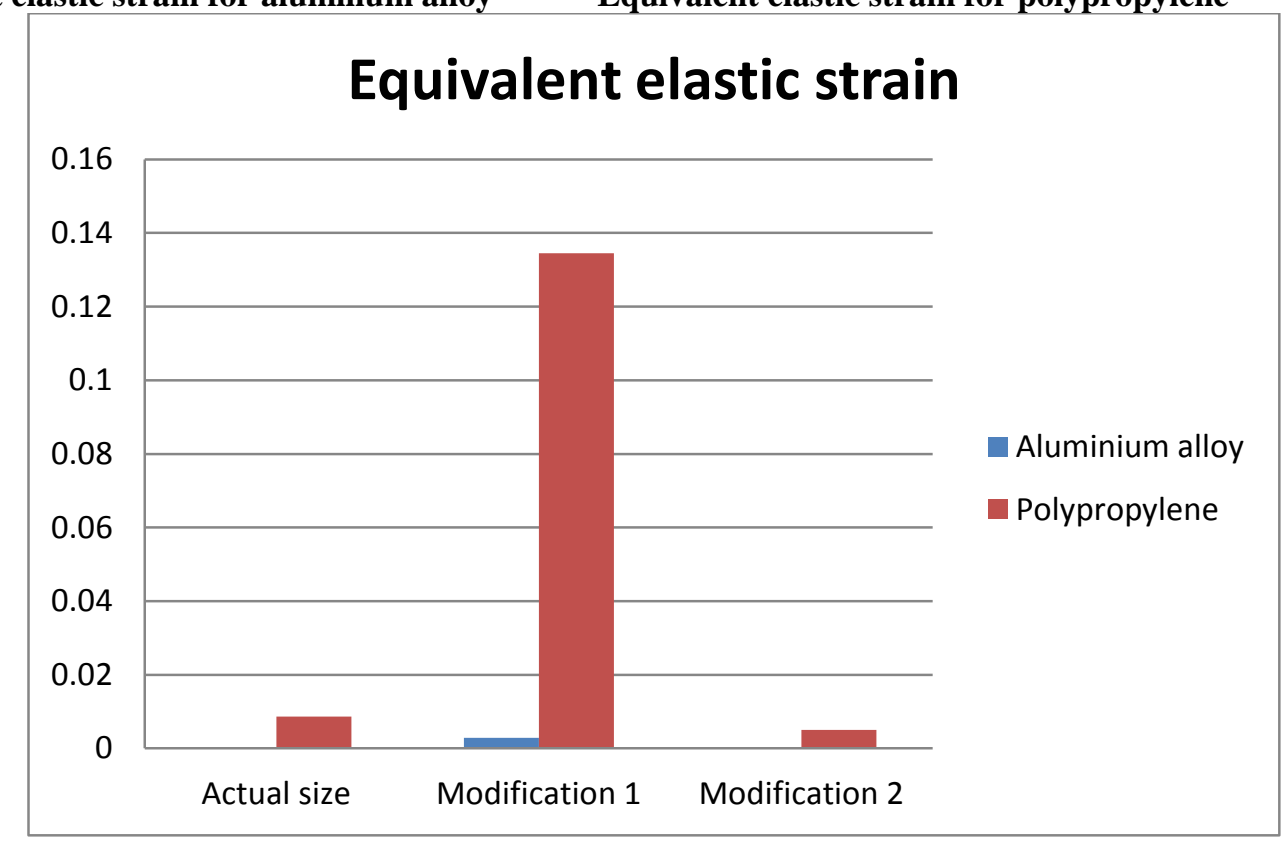




\begin{tabular}{|c|c|c|}
\hline Equivalent elastic strain & Aluminum alloy & Polypropylene \\
\hline Actual size & 0.00022844 & 0.0086349 \\
\hline Modification 1 & 0.0028406 & 0.13456 \\
\hline Modification 2 & 0.0001281 & 0.0050508 \\
\hline
\end{tabular}

\section{SHEAR STRESS}

\section{Actual size}

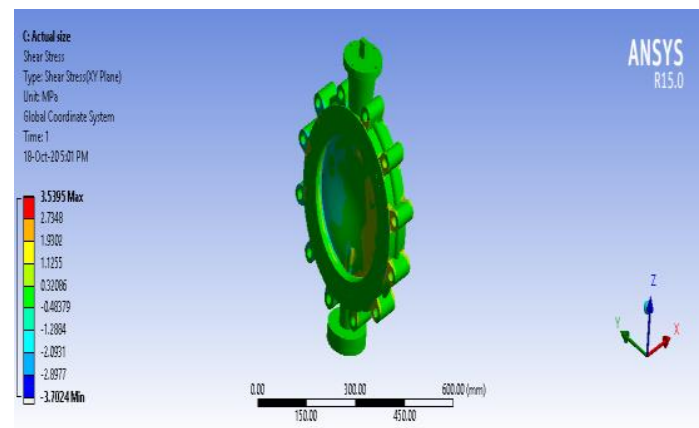

Shear stress for aluminum alloy

\section{Modification 1}
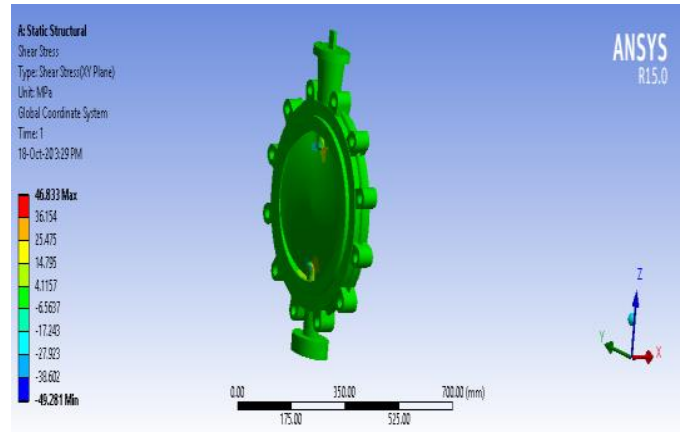

Shear stress for aluminum alloy

\section{Modification 2}

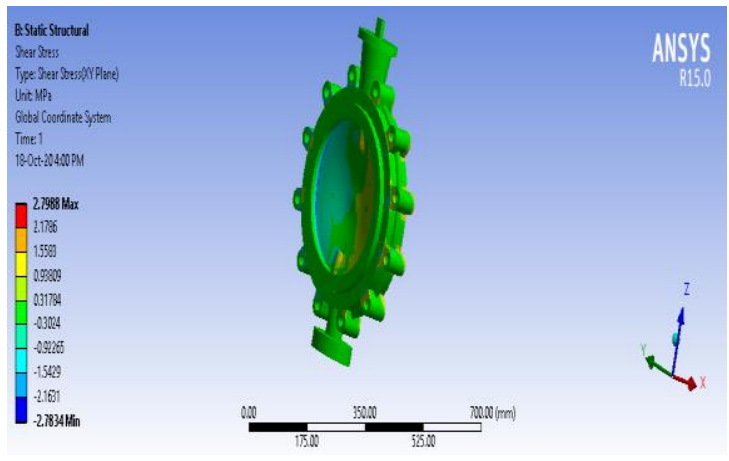

Shear stress for aluminum alloy

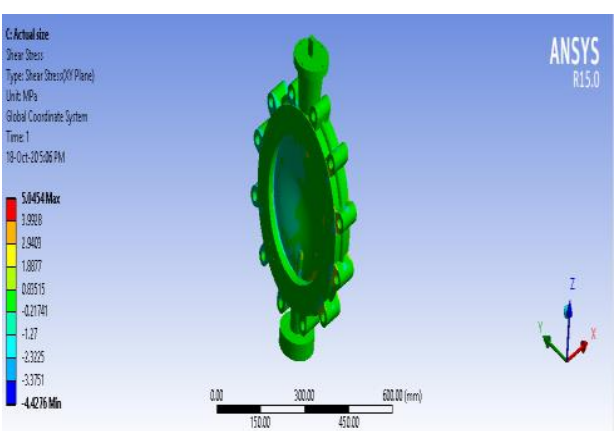

Shear stress for polypropylene

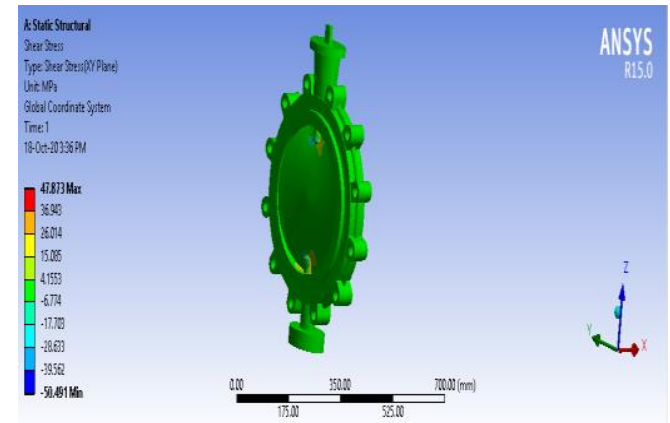

Shear stress for polypropylene

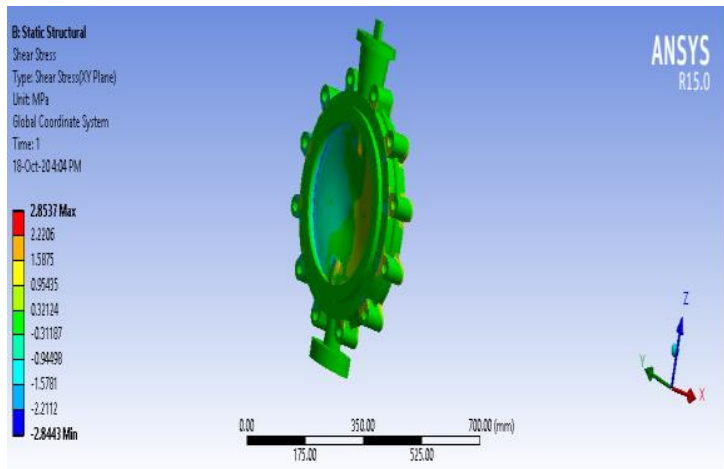

Shear stress for polypropylene 


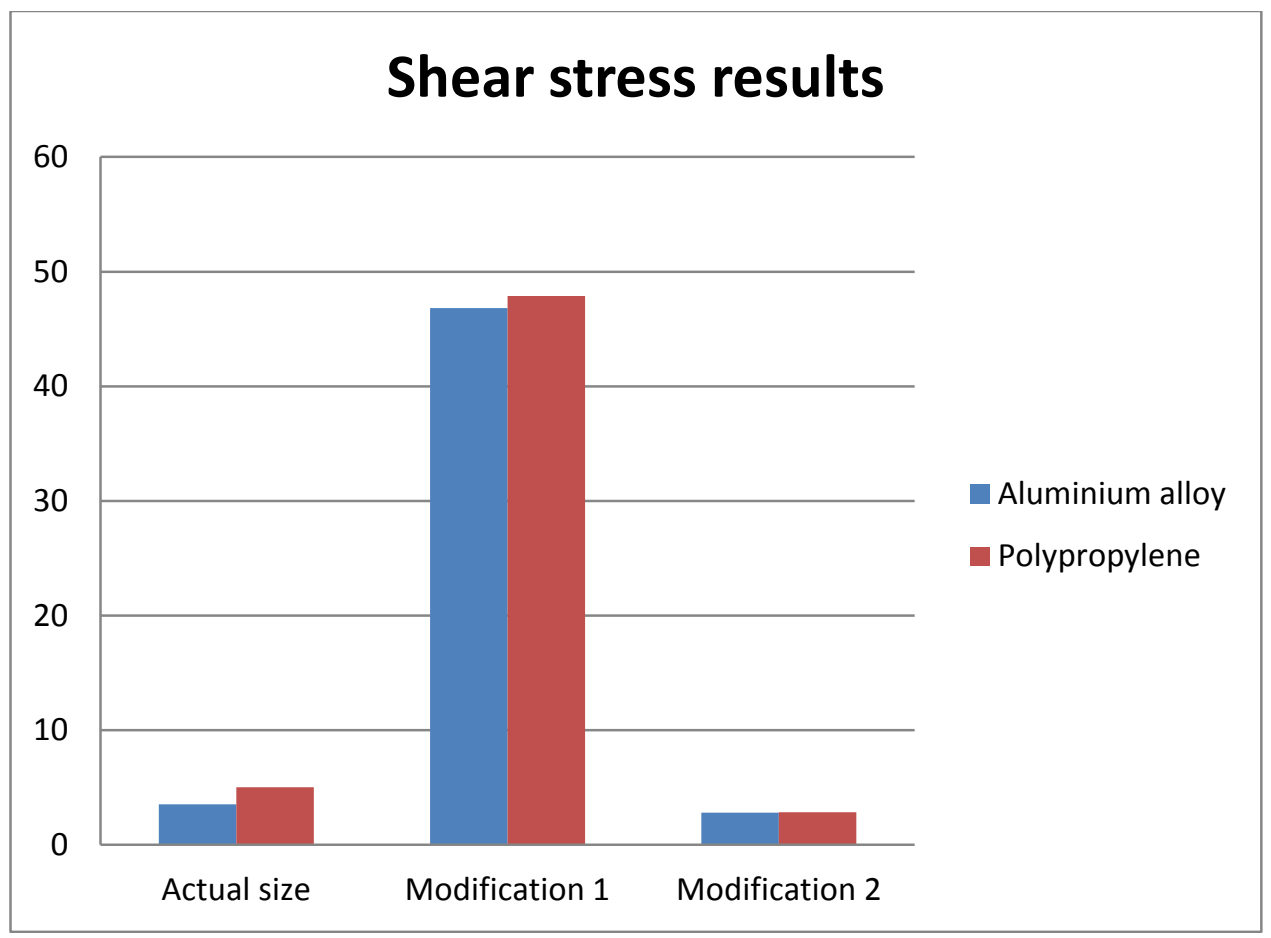

\begin{tabular}{|c|c|c|}
\hline Shear stress & Aluminum alloy & Polypropylene \\
\hline Actual size & 3.5395 & 5.0454 \\
\hline Modification 1 & 46.833 & 47.873 \\
\hline Modification 2 & 2.7988 & 2.8537 \\
\hline
\end{tabular}

\section{Equivalent stress}

\section{Actual size}

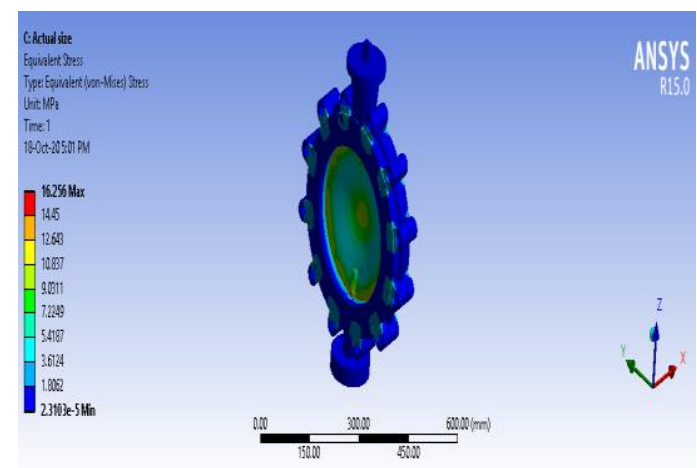

Equivalent stress for aluminum alloy

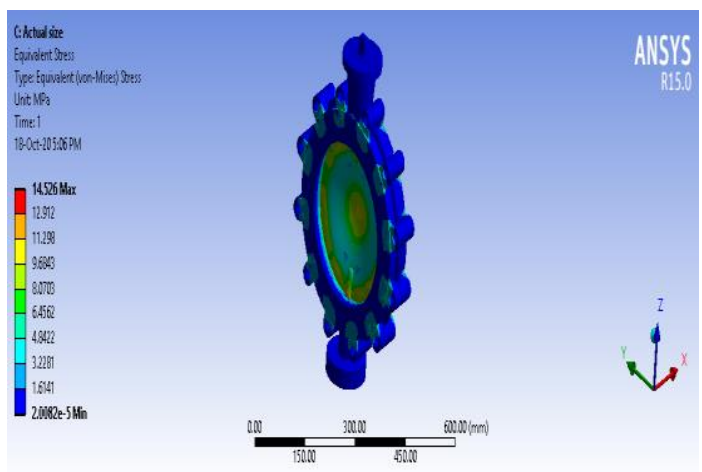

Equivalent stress for polypropylene 


\section{Modification 1}

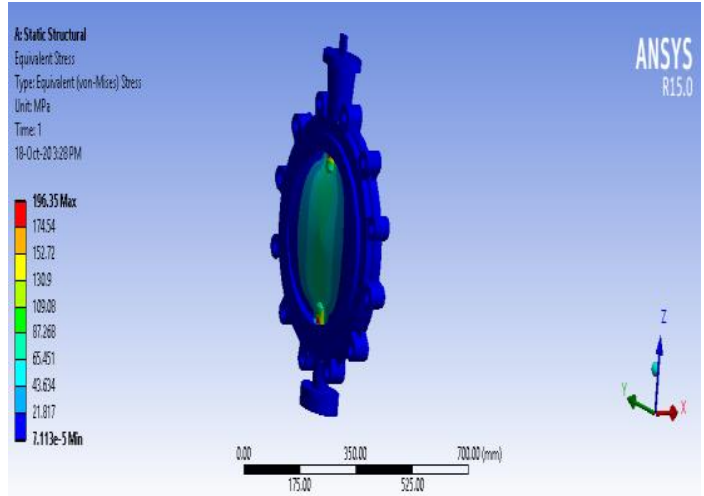

Equivalent stress for aluminum alloy

\section{Modification 2}
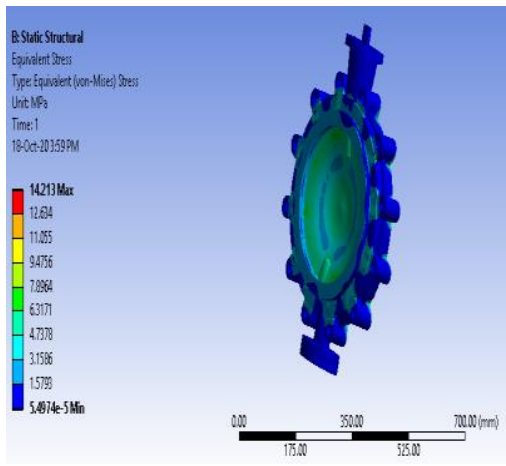

Equivalent stress for aluminum alloy
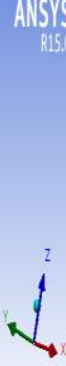

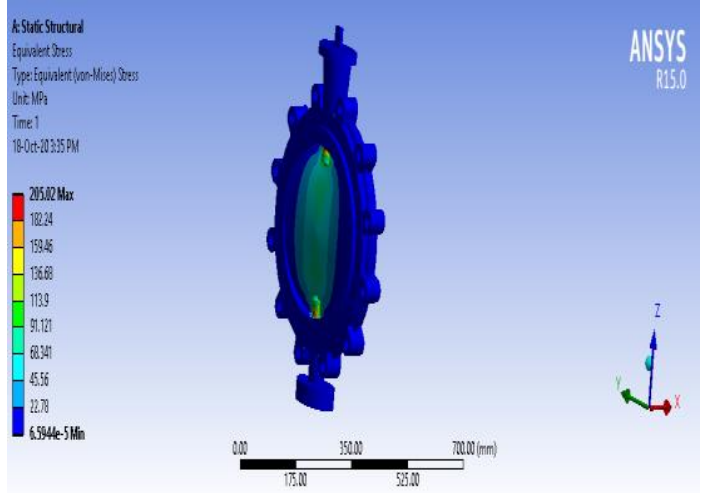

Equivalent stress for polypropylene

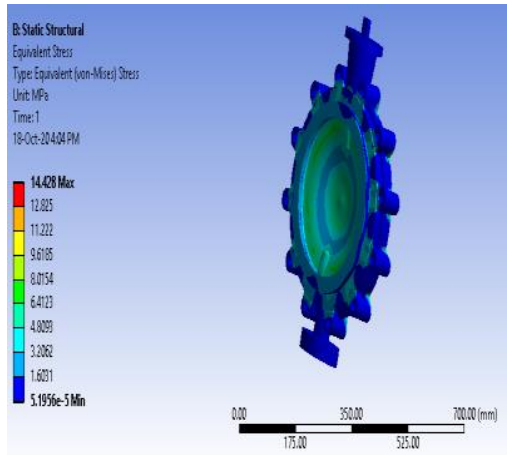

ANSYS

Equivalent stress for polypropylene

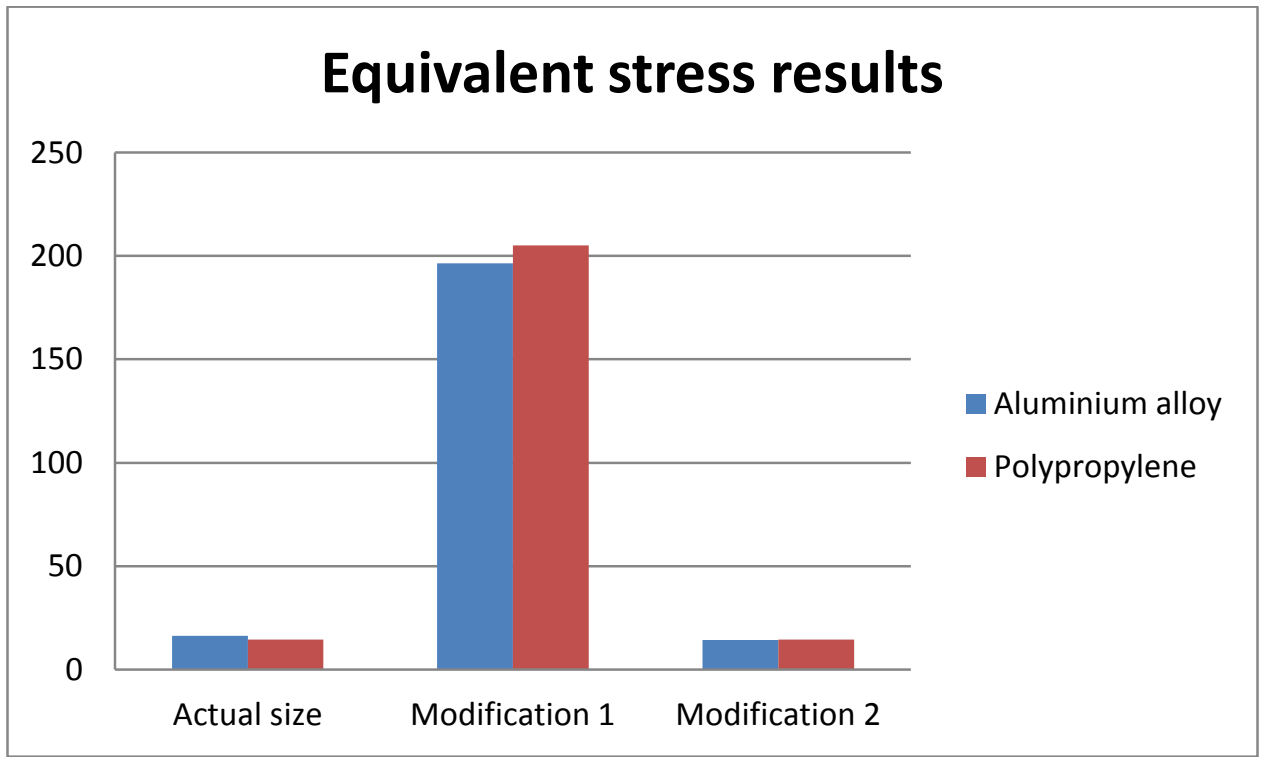




\begin{tabular}{|c|c|c|}
\hline Equivalent stress & Aluminum alloy & Polypropylene \\
\hline Actual size & 16.256 & 14.526 \\
\hline Modification 1 & 196.35 & 205.02 \\
\hline Modification 2 & 14.213 & 14.428 \\
\hline
\end{tabular}

\section{Conclusion:}

The butterfly valve result analysis results show the structural deformations and stress in the valves, now a days plastic valves are used for replacement of metallic valves, in this analysis polypropylene material show the better results compare to the aluminium alloy, adding the elliptical structure modifications give the better results in both materials and structural stability also

\section{REFERENCES}

1. Journal on "Offset Disc Butterfly Valve Design" by Dr.Ullas D R and P.V. Sreehari

2. Journal on "Design and Development of Double Offset Butterfly Valve" by Piyush. P and S. Tajane

3. [3] Journal on "Statistical Methods to Optimize process parameters to Minimize casting Defects", a project done in Akaki Based Metal Industries, Ethiopia

4. Journal on "Shrinkage Cavity Analysis in Butterfly Valve Disc Casting" by K. Anish Raj, Jinoy Mathew, and Jeffin Johnson

5. Journal on "Weight Optimisation" by Mr. Sridhar .S. Gurav and Dr. S.A Patil

6. Journal on "Design, Development and Testing of Butterfly valve leakage test Rig" by P.K. Parasel and M.V Kavade

7. Journal on "Optimisation of Sand Casting Process Variables" by A Kumaravadivel and U Natarajan

8. Book on "Foundary Technology" by Stephen I Karsey

9. Ogawa, K. and Kimura,T. Hydrodynamic characteristics of a butterfly valve - prediction of torque characteristic. ISA Trans., 1995, 34, 327-333. Proc. IMechE Vol. 223 Part E: J. Process Mechanical Engineering JPME236 () IMechE 2009 Downloaded from pie.sagepub.com at DONG A UNIV LIBRARY on July 11, 2011 Analysis and optimization of butterfly valve disc 89.

10. Huang, C. D. and Kim, R. H. Three-dimensional analysis of partially open butterfly valve flows. Trans. ASME, J. Fluids Eng., 1996, 118, 562-568. 